\title{
La identidad profesional del educador social a través de su perfil competencial
}

\section{The Professional Identity of the Social Educator Through his Competency Profile}

\author{
María Dolores Eslava-Suanes, I gnacio González-López, Carlota de-León-Huertas \\ Universidad de Córdoba, Departamento de Educación, Avda. San Alberto Magno, s/n - 14071 Córdoba \\ \{mdolores.eslava; ignacio.gonzalez; carlota.leon.huertas\}@uco.es \\ http://orcid.org/0000-0002-7148-7106, http://orcid.org/0000-0002-9114-4370, http://orcid.org/0000-0002-7125-8637
}

Esta investigación se ha realizado con el apoyo del Ministerio de Educación, Cultura y Deporte (ES) a través de la beca de Formación del Profesorado Universitario 2013/01529

\section{Resumen}

La finalidad de este trabajo es definir el perfil competencial de la educación social, lo que implica valorar en qué medida las competencias propuestas son necesarias según la percepción de los profesionales. El estudio se enmarca en un diseño mixto complejo gestionado, al amparo de tres grupos de discusión con educadoras y educadores sociales, a través de cuatro momentos de trabajo: análisis previo de la situación profesional intrínseca y extrínseca del educador o educadora social por medio de una matriz DAFO, valoración del modelo de competencias a través de un cuestionario de naturaleza cuantitativa que incorpora el uso de escalas, discusión con los diferentes grupos de educadoras y educadores sociales para construir una visión consensuada de la profesión y diseño de propuestas de mejora con la aplicación de una matriz CAME. La riqueza de los resultados extraídos ha permitido redefinir un perfil competencial con el que el profesional de la educación social se siente identificado. Dicho perfil está compuesto por 23 competencias agrupadas en seis dimensiones: competencias comunicativas, competencias crítico-reflexivas, competencias sociales, conocimientos disciplinares, competencias funcionales y competencias definitorias de la identidad profesional.

\section{Palabras clave}

Identidad profesional; Grupo de discusión; Educación social; Perfil competencial

\section{Abstract}

The purpose of this work is to define the competency profile of the social education, which involves assessing to what extent the proposed competencies are necessary according to the perception of professionals. The study is framed in a complex managed mixed design, under three discussion groups with social educators, through four working moments: previous analysis of the intrinsic and extrinsic professional situation of the social educator by means of a SWOT matrix, valuation of the model of competencies through a quantitative questionnaire that incorporates the use of scales, discussion with the different groups of social educators to build a consensus vision of the profession and design proposals for improvement with the application of a CAME matrix. The richness of the extracted results has allowed to redefine a competency profile with which the social educator feels identified. This profile is made up of 23 competences grouped in six dimensions: communicative competencies, critical-reflexive competencies, social competencies, disciplinary knowledge, functional competencies and defining competencies of professional identity.

\section{Keywords}

Professional Identity; Discussion Group; Social Education; Competency Profile 


\section{Introducción}

Como técnica de investigación social, el grupo de discusión es, en palabras de Huertas y Vigier (2010, p. 183), "una reunión de un grupo de personas que poseen ciertas características comunes, guiada por un moderador y diseñada con el objetivo de obtener información sobre un tema específico en un espacio y en un tiempo determinado". Se nutre del diálogo reorganizado y revisado por el cómputo del grupo bajo consenso, por lo tanto, no se obtienen datos aislados, sino la reconstrucción de un pensamiento (Álvarez Rojo, 1990; Canales y Peinado, 1995).

Los grupos de discusión son artificiales y adquieren unidad durante el proceso, dándose dos tipos de relaciones: la que une a cada persona con el grupo y la que vincula al grupo con el investigador o investigadora, es decir, se constituyen como tal en el mismo momento en el que cada interlocutor o interlocutora se acopla en el desarrollo del discurso, lo que facilita las relaciones simétricas al realizar la tarea, siendo la opinión grupal la que garantiza la validez del producto en su totalidad al reconstruir el sentir del grupo en un contexto discursivo y dialogante (Gil, 1992; Canales y Peinado, 1995; Suárez, 2005).

El diseño del grupo de discusión constituye una parte prioritaria para su implementación siendo fundamental la planificación del contenido a tratar, así como los objetivos a perseguir (Canales y Peinado, 1995). Suárez (2005) establece seis fases de carácter flexible con las que desarrollar este proceso: exploratoria, preparatoria, de implementación, de análisis e interpretación, informativa y de retroalimentación.

Siguiendo estas fases, es importante remarcar algunas apreciaciones en torno a la configuración de los grupos de discusión. Canales y Peinado (1995) y Barbour (2013) destacan la importancia de definir el número total de grupos y las variables definitorias para cada uno de ellos, así como la dispersión geográfica de los mismos, ya que, si con la muestra se busca la representación de la población, buscando las personas determinadas relevantes a priori en este campo, se han de combinar sus atributos definitorios acorde a unos mínimos tanto de heterogeneidad como de homogeneidad que garanticen la idoneidad del grupo. Concretamente, Gil (1992) señala que lo ideal sería realizar tantos grupos de discusión como segmentos de la población objeto de estudio, de manera que se abarque a todo el espectro representativo, acordado como mínimo tres o cuatro y como máximo diez o doce.

Respecto al número de integrantes de cada grupo de discusión, Álvarez Rojo (1990) y Bisquerra (2004) recomiendan que esté compuesto por entre cinco y diez personas para facilitar el diálogo, siendo siete el número óptimo para facilitar la participación y comunicación de todos y de todas. Teniendo en cuenta que la selección de los participantes no responde a criterios estadísticos, sino que se rige 
por la calidad del conjunto de relaciones que se puedan dar, se lleva a cabo un muestreo intencional (Fábregues, Meneses, Rodríguez-Gómez y Paré, 2016).

La duración de la discusión no deberá ser superior a una hora y media, para no cargar a los participantes (Mena y Méndez, 2009).

Otro de los elementos fundamentales en la puesta en práctica de esta herramienta es la figura de la moderadora o moderador, persona encargada no solo de dirigir la sesión, sino de cerciorarse de que los participantes no se conocen entre sí, de controlar el tiempo para que cada persona tenga su momento para expresarse, de inaugurar y clausurar la sesión, de registrar el orden y el contenido inicial de la interlocución de cada persona, de convocar al grupo, de disponer de un espacio y mobiliario, de registrar diálogo producido con una grabadora o un vídeo, etc. (Canales y Peinado, 1995 y Bisquerra, 2004).

\subsection{Bondades y limitaciones de los grupos de discusión}

El grupo de discusión facilita el acceso a información proveniente de situaciones reales y naturales, ofreciendo unos resultados creíbles, ya que esta técnica posee una alta validez subjetiva. Respecto al formato, al ser un discurso no estructurado, el moderador o moderadora tiene la posibilidad de indagar y explorar en aspectos del tema que no se hayan desarrollado con la profundidad deseada (Bisquerra, 2004).

Así mismo, tanto el análisis como la recolección de información van en paralelo, permitiéndole al investigador buscar temas emergentes y patrones comunes en los diferentes grupos de discusión realizados (Mena y Méndez, 2009).

Sin embargo, también presenta algunas desventajas como la incapacidad del moderador o moderadora para controlar si los participantes se influyen entre sí, si aparecen temas irrelevantes, si la discusión se focaliza en un tema, e incluso la complejidad para analizar los datos cuando los y las participantes deciden modificar su opinión o interrumpen a otro en su diálogo (Callejo, 2001; Bisquerra, 2004; Suárez, 2005). Teniendo en cuenta que la función del moderador debe ser presentar el tema y dar pie a la discusión sin intervenir en la misma (Álvarez Rojo, 1990).

Con respecto a la homogeneidad o heterogeneidad del grupo, Fábregues, Meneses, Rodríguez-Gómez

y Paré (2016) señalan que si los miembros comparten muchas características se corre el riesgo de que adopten un diálogo común e integrado.

En relación al número de miembros que componen cada grupo de discusión, un grupo muy numeroso puede llegar a ser difícil de moderar si los participantes perciben que no disponen del tiempo suficiente 
para expresar su postura. No obstante, los grupos demasiado reducidos corren el riesgo de cancelarse en caso de que haya bajas o de saturar rápidamente la información al llegar apresuradamente a un consenso (Fábregues, Meneses, Rodríguez-Gómez y Paré, 2016).

Canales y Peinado (1995) y Bisquerra (2004) indican la necesidad de ser cautelosos con la elección del lugar donde se realicen los grupos de discusión, ya que podrían sesgar la opinión de los participantes. Sin embargo, Barbour (2013) advierte que no existe ningún escenario neutral, cualquier escenario puede condicionar la participación de los participantes en la medida en que se aproxime o se aleje de su zona de confort.

\section{Objetivos}

El objetivo de este trabajo es definir el perfil competencial del profesional de la educación social, desarrollado a partir del estudio documental comparativo y su posterior validación por un panel de expertos y expertas del ámbito universitario, lo que implica valorar en qué medida las competencias propuestas son necesarias para el desempeño de la educación social según la percepción de sus profesionales.

\section{Metodología}

Se lleva a cabo un diseño mixto, ya que supone la recopilación y el análisis de datos desde ambos enfoques en un mismo estudio (Creswell \& Plano-Clark, 2007). Siguiendo a Hernández, Fernández y Baptista (2006) el método mixto no consiste únicamente en la recolección de datos de diferente naturaleza sobre el mismo fenómeno, sino que implica un planteamiento inicial del problema de investigación que contemple el método inductivo y deductivo. Dentro de los diseños definidos por estos autores nos posicionamos en un diseño mixto complejo, también denominado diseño de triangulación, ya que implica la recogida de datos cualitativos y cuantitativos en un proceso iterativo donde se mezclan diferentes diseños, ofreciendo diseños exclusivos.

En esta investigación el diseño se gestiona a través de cuatro momentos de trabajo sustentados en la realización de un grupo de discusión en el que converge de manera concurrente información de corte cualitativo y cuantitativo con diferente grado de dominancia: inicialmente se analiza la situación profesional del educador o educadora social a través de una matriz DAFO; en un segundo momento, se valora el modelo de competencias a través de un cuestionario de naturaleza cuantitativa que incorpora el uso de elementos escalares; en tercer lugar, se realiza la discusión a través de preguntas estímulo, a fin de construir una visión consensuada de la profesión; finalmente, se propone el diseño de propuestas de mejora gracias a la aplicación de una matriz CAME. 
La muestra está formada por 23 educadores y educadoras sociales, 12 mujeres y 11 varones con edad media de 37 años, distribuidos en tres grupos de discusión celebrados en colaboración con la Universidad de Salamanca (seis participantes), Córdoba (diez participantes) y Valencia (siete participantes).

\section{Resultados}

Buscando el consenso entre los tres grupos de discusión realizados en Salamanca, Córdoba y Valencia, y atendiendo a las fases en las que se ha recabado la información, se presentan a continuación los resultados extraídos.

\subsection{Resultados de las matrices DAFO}

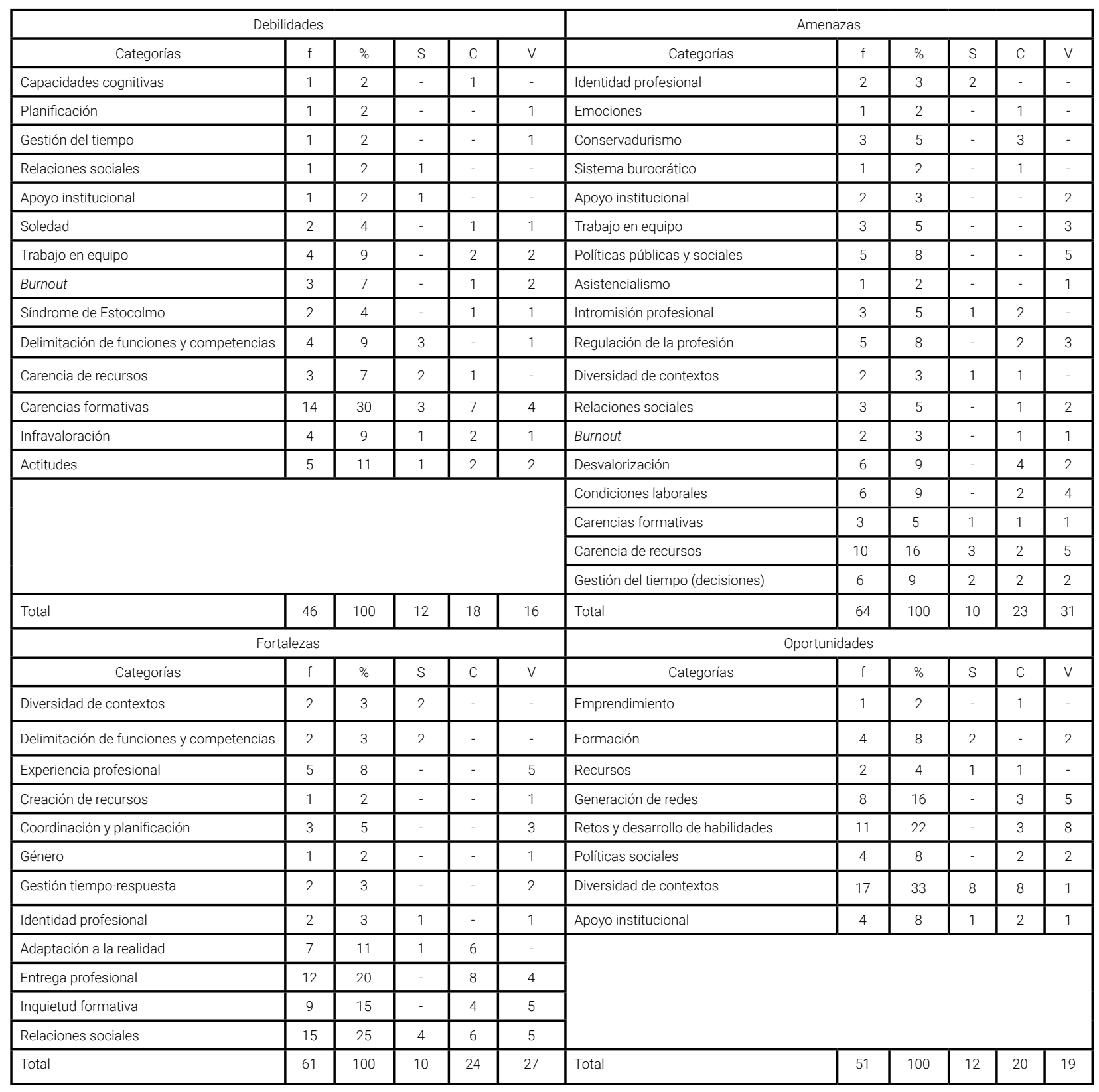

Tabla 1. Análisis global de las matrices DAFO 
Reflejados los tres grupos de discusión (tabla 1) a través de sus iniciales (S, C y V), los y las profesionales de la educación social coinciden en destacar como debilidades de la profesión las carencias formativas con un peso del 30\%, ya que demandan más formación teórica-práctica, pero sobre todo específica y focalizada en las áreas de acción socioeducativa.

Otra categoría en la que coinciden, aunque con menor presencia (11\%) es en destacar sus características, actitudes o rasgos de personalidad, como factores que dificultan su labor profesional: impulsividad, impaciencia, desmotivación, introversión, etc. Además, tienen el mismo parecer en cuanto al sentimiento de infravaloración, motivado por la falta de referentes y la inseguridad ante la toma de decisiones (9\%).

Atendiendo a las categorías en las que solo coinciden dos de los grupos, Córdoba y Valencia advierten debilidades a la hora de trabajar en equipo debido a la falta de coordinación y a la adopción de diferentes puntos de vista (9\%). Salamanca y Valencia señalan como debilidad el desconocimiento de sus propias funciones y competencias, no de manera generalizada, sino la delimitación de las mismas con las de otros y otras profesionales (9\%). Por otro lado, Salamanca y Córdoba destacan la falta de recursos $(7 \%)$.

Con relación a las fortalezas, la categoría con más presencia y en la que coinciden los tres grupos, es la vinculada a las relaciones sociales (25\%), lo que les capacita para empatizar, realizar un buen diagnóstico y adaptar la acción socioeducativa a la realidad.

Los educadores y educadoras sociales de Córdoba y Valencia destacan como fortaleza la entrega profesional (20\%), en cuanto la educación social les precisa mucha capacidad de trabajo, constancia, persecución y proyección de metas y resiliencia. Así mismo, estos profesionales destacan su inquietud por la formación continua (15\%). Los y las profesionales de Salamanca y Córdoba resaltan su capacidad de adaptación (11\%), considerándose reflexivos y resolutivos.

Con respecto a las amenazas, todos los grupos hallan la carencia de recursos (16\%). Así mismo, comparten la existencia de carencias formativas, destacando la existencia de profesionales que se han construido desde la práctica y no tienen iniciativa hacia la formación continua (5\%). El factor tiempo (9\%) también es considerado una amenaza, en cuanto a la capacidad de adaptación del profesional a la respuesta educativa instantánea (atención a la urgencia).

LascategoríasconmáspresenciaenlasquecoincidenlosgruposdeCórdobay Valenciaestánrelacionadas con la desvalorización social de las funciones que realiza este profesional (9\%), las malas condiciones laborales que condicionan una inestabilidad económica y laboral (9\%) y todo ello como consecuencia de ser una profesión que no está regulada (8\%). Así pues, esto mantiene relación con una categoría destacada por los grupos de Salamanca y Córdoba, como es la intromisión profesional (5\%). 
Coinciden al señalar la diversidad de áreas de acción socioeducativa (33\%) como una de las oportunidades que le brinda la profesión y que favorece la búsqueda de nuevos yacimientos de empleo y la incorporación al mercado laboral.

Para los y las profesionales de Córdoba y Valencia, el desempeño profesional supone un reto personal y como tal les permite el desarrollo de habilidades que favorecen la innovación, el liderazgo, la creatividad y la calidad de la acción socioeducativa (22\%). Este grupo encuentra en la profesión una oportunidad para generar redes sociales y sinergias entre profesionales para trabajar en equipo y coordinar la acción socioeducativa (16\%).

\subsection{Resultados de la implementación del cuestionario}

Atendiendo a los resultados de la escala de estimación, los datos ponen de manifiesto que las competencias expuestas son relevantes para el desempeño de su profesión, siendo la discrepancia entre las diferentes puntuaciones muy baja (tabla 2).

Para verificar la normalidad de la muestra que permita la aplicación de la prueba ANOVA en atención a la universidad de procedencia de los grupos participantes, se ha aplicado una prueba de chi cuadrado, que arroja un valor $p=.568$, lo que indica que se asume el principio de normalidad de la muestra. Por otro lado, se cumple el principio de homocedasticidad en el $65 \%$ de los elementos considerados.

\begin{tabular}{|c|c|c|c|c|c|c|c|c|c|c|}
\hline \multirow{2}{*}{ Competencias } & \multicolumn{2}{|c|}{$\begin{array}{l}\text { Univ. de } \\
\text { Salamanca }\end{array}$} & \multicolumn{2}{|c|}{$\begin{array}{l}\text { Univ. de } \\
\text { Córdoba }\end{array}$} & \multicolumn{2}{|c|}{$\begin{array}{l}\text { Univ. de } \\
\text { Valencia }\end{array}$} & \multicolumn{2}{|c|}{ Global } & \multicolumn{2}{|c|}{ Anova } \\
\hline & $M$ & $S$ & $M$ & $S$ & $M$ & $S$ & M & $S$ & $\mathrm{~F}$ & Sig \\
\hline $\begin{array}{c}\text { Hacer un uso efectivo de las tecnologías de } \\
\text { la información y la comunicación aplicadas } \\
\text { a la formación y a la comunicación en los } \\
\text { procesos de gestión, organización y acción } \\
\text { socioeducativa. }\end{array}$ & 4.00 & 0.63 & 4.3 & 0.48 & 3.57 & 1.27 & 4 & 0.85 & 1.58 & .230 \\
\hline $\begin{array}{c}\text { Dominar una segunda lengua de forma oral y } \\
\text { escrita con el fin de favorecer la comunicación } \\
\text { y las relaciones al trabajar en entornos } \\
\text { multiculturales. }\end{array}$ & 3.33 & 0.82 & 3 & 0.67 & 3.71 & 0.95 & 3.3 & 0.82 & 1.65 & .217 \\
\hline $\begin{array}{l}\text { Comprender los referentes teóricos y } \\
\text { contextuales que configuran al ser humano } \\
\text { como protagonista de la educación y su } \\
\text { aplicación a los distintos ámbitos y grupos de } \\
\text { acción. }\end{array}$ & 4.00 & 0.63 & 4 & 0.94 & 3.57 & 1.27 & 3.87 & 0.97 & 0.45 & .642 \\
\hline $\begin{array}{l}\text { Identificar y emitir juicios razonados sobre } \\
\text { problemas socioeducativos relacionados con } \\
\text { la práctica profesional. }\end{array}$ & 4.67 & 0.52 & 4.5 & 0.53 & 4.43 & 0.54 & 4.52 & 0.51 & 0.35 & .712 \\
\hline $\begin{array}{l}\text { Tomar decisiones respecto a la práctica } \\
\text { socioeducativa teniendo en cuenta las } \\
\text { consecuencias para todas las partes } \\
\text { implicadas. }\end{array}$ & 4.67 & 0.82 & 4.4 & 0.7 & 4.71 & 0.49 & 4.57 & 0.66 & 0.54 & .594 \\
\hline $\begin{array}{c}\text { Analizar, sintetizar e interpretar la información } \\
\text { que proporciona el trabajo cotidiano y los } \\
\text { medios de información y comunicación } \\
\text { con la finalidad de mejorar las estrategias } \\
\text { profesionales de acción. }\end{array}$ & 4.33 & 0.52 & 4.6 & 0.52 & 4.43 & 0.79 & 4.48 & 0.59 & 0.39 & 681 \\
\hline $\begin{array}{c}\text { Desarrollar una actitud empática, respetuosa, } \\
\text { solidaria y de confianza hacia las personas e } \\
\text { instituciones sujetos de la acción socioedu- } \\
\text { cativa. }\end{array}$ & 5.00 & 0 & 4.7 & 0.68 & 4.71 & 0.49 & 4.78 & 0.52 & 0.7 & .511 \\
\hline
\end{tabular}




\begin{tabular}{|c|c|c|c|c|c|c|c|c|c|c|}
\hline \multirow{2}{*}{ Competencias } & \multicolumn{2}{|c|}{$\begin{array}{l}\text { Univ. de } \\
\text { Salamanca }\end{array}$} & \multicolumn{2}{|c|}{ Univ. de Córdoba } & \multicolumn{2}{|c|}{ Univ. de Valencia } & \multicolumn{2}{|c|}{ Global } & \multicolumn{2}{|c|}{ Anova } \\
\hline & $M$ & $S$ & $\mathrm{M}$ & $S$ & $M$ & $S$ & $\mathrm{M}$ & $S$ & $\mathrm{~F}$ & Sig \\
\hline $\begin{array}{l}\text { Conocer e interpretar la deontología, } \\
\text { evolución y modelos del ejercicio de la } \\
\text { profesión de la educación social, así } \\
\text { como los supuestos pedagógicos para la } \\
\text { adecuación profesional a los diferentes } \\
\text { ámbitos de acción socioeducativa. }\end{array}$ & 4.67 & 0.82 & 4.1 & 0.74 & 3.86 & 1.22 & 4.17 & 0.94 & 1.3 & .296 \\
\hline $\begin{array}{l}\text { Conocer la evolución del conocimiento } \\
\text { educativo al amparo de las teorías y } \\
\text { enfoques pedagógicos y bases legislativas } \\
\text { que a lo largo del quehacer educativo se han } \\
\text { ido construyendo. }\end{array}$ & 4,17 & 0.75 & 3.5 & 1.08 & 3.14 & 0.9 & 3.57 & 0.99 & 1.9 & .175 \\
\hline $\begin{array}{c}\text { Conocer la evolución histórica de la } \\
\text { educación social a nivel comunitario, estatal, } \\
\text { europeo e internacional para comprender } \\
\text { la configuración de su campo e identidad } \\
\text { profesional. }\end{array}$ & 3.67 & 0.82 & 3.5 & 1.08 & 3.29 & 0.95 & 3.48 & 0.95 & 0.25 & .783 \\
\hline $\begin{array}{l}\text { Conocer los principios y fundamentos de } \\
\text { acción de la inclusión para la adecuación de } \\
\text { la respuesta socioeducativa. }\end{array}$ & 4.67 & 0.52 & 4.2 & 0.92 & 4.29 & 0.76 & 4.35 & 0.78 & 0.7 & .512 \\
\hline $\begin{array}{l}\text { Conocer los estadios evolutivos y el } \\
\text { desarrollo madurativo en las diferentes } \\
\text { áreas: motora, cognitiva, comunicativa y } \\
\text { socioafectiva, con la finalidad de adecuar la } \\
\text { acción socioeducativa de la población con la } \\
\text { que se trabaja. }\end{array}$ & 4.50 & 0.84 & 4.5 & 0.53 & 4.14 & 1.07 & 4.39 & 0.78 & 0.48 & .624 \\
\hline $\begin{array}{l}\text { Conocer y comprender la dinámica de } \\
\text { construcción social de la realidad, el proceso } \\
\text { de socialización de las personas. }\end{array}$ & 4.33 & 0.52 & 4.5 & 0.53 & 4 & 1 & 4.3 & 0.70 & 1.05 & .367 \\
\hline $\begin{array}{l}\text { Conocer y aplicar la mirada antropológica } \\
\text { en el desarrollo de su profesión a través del } \\
\text { uso crítico del relativismo cultural en normas } \\
\text { sociales, políticas, filosóficas y religiosas. }\end{array}$ & 4.00 & 0 & 4.1 & 0.88 & 3.57 & 0.98 & 3.91 & 0.79 & 0.96 & .400 \\
\hline $\begin{array}{l}\text { Dinamizar actividades que fomenten la } \\
\text { transformación sociocultural desde el respeto } \\
\text { a los valores culturales de la diversidad. }\end{array}$ & 4.50 & 0.55 & 4.4 & 0.7 & 4.29 & 0.76 & 4.39 & 0.66 & 0.16 & .853 \\
\hline $\begin{array}{c}\text { Aplicar las distintas estrategias } \\
\text { metodológicas y técnicas de acción } \\
\text { individual, grupal y comunitaria para facilitar } \\
\text { las interacciones sociales. }\end{array}$ & 4.83 & 0.41 & 4.5 & 0.85 & 4.57 & 0.54 & 4.61 & 0.66 & 0.48 & .628 \\
\hline $\begin{array}{l}\text { Elaborar, utilizar y evaluar recursos } \\
\text { educativos e instrumentos de recogida de } \\
\text { información para enriquecer y mejorar los } \\
\text { procesos y contextos educativos y sociales. }\end{array}$ & 4.67 & 0.52 & 4.5 & 0.71 & 4.29 & 0.76 & 4.48 & 0.67 & 0.52 & .605 \\
\hline $\begin{array}{c}\text { Aplicar técnicas de resolución de conflictos } \\
\text { para mediar e intervenir, asesorando, } \\
\text { acompañando y promocionando a personas } \\
\text { y grupos. }\end{array}$ & 5.00 & 0 & 4.7 & 0.71 & 4.86 & 0.38 & 4.82 & 0.50 & 0.81 & .458 \\
\hline $\begin{array}{l}\text { Investigar los contextos sociales, culturales } \\
\text { y educativos para detectar las demandas de } \\
\text { acción en escenarios socioeducativos. }\end{array}$ & 4.83 & 0.41 & 4.6 & 0.52 & 4.43 & 0.79 & 4.61 & 0.58 & 0.76 & .479 \\
\hline $\begin{array}{l}\text { Elaborar, aplicar y evaluar planes, programas } \\
\text { y proyectos de acción socioeducativa en } \\
\text { diversos contextos. }\end{array}$ & 4.83 & 0.41 & 4.4 & 0.84 & 4.43 & 0.54 & 4.52 & 0.67 & 0.89 & .428 \\
\hline $\begin{array}{l}\text { Gestionar y coordinar centros, instituciones } \\
\text { y asociaciones de acuerdo a los diferentes } \\
\text { contextos y necesidades en los ámbitos de } \\
\text { acción socioeducativa. }\end{array}$ & 4.00 & 0.63 & 4.1 & 0.88 & 4.43 & 0.54 & 4.17 & 0.72 & 0.65 & .533 \\
\hline $\begin{array}{l}\text { Mantener el compromiso ético en la acción e } \\
\text { investigación socioeducativa. }\end{array}$ & 4.83 & 0.41 & 4.8 & 0.42 & 4 & 1.16 & 4.57 & 0.79 & 3.09 & .068 \\
\hline $\begin{array}{c}\text { Desarrollar y fortalecer el conocimiento de sí } \\
\text { mismo (autocuidado, autocontrol, equilibrio } \\
\text { emocional, manejo del estrés y control de la } \\
\text { incertidumbre durante la acción socioeduca- } \\
\text { tiva) como base del crecimiento, integración } \\
\text { y actualización de la potencial profesional- } \\
\text { ización. }\end{array}$ & 4.83 & 0.41 & 4.9 & 0.32 & 4.43 & 0.54 & 4.74 & 0.45 & 2.86 & .081 \\
\hline
\end{tabular}


Con respecto a las dimensiones en las que se organiza el modelo, ha sido la competencia que hace referencia al uso y dominio de una lengua extranjera la menos valorada, con una media de 3,3 , seguida de aquellas competencias correspondientes a los conocimientos disciplinares, teoría de la educación social e historia de la educación social, con una media de 3,57 y 3,48 respectivamente.

No obstante, las competencias más valoradas han sido la competencia funcional "Mediación, social, cultural y educativa", con una media de 4,82, seguida de la competencia social "Relaciones sociales", con una media de 4,78; y aquella relacionada con la identidad profesional como base para desarrollar y fortalecer el conocimiento de sí mismo, con una media de 4,74.

Por otro lado, no se observan diferencias significativas entre las puntuaciones dadas por los educadores y educadoras sociales de cada comunidad autónoma una vez realizado un Análisis de Varianza de un Factor (ANOVA) (n.s.=,05), lo que indica que la zona geográfica no condiciona el perfil competencial del educador o educadora social.

\subsection{Resultado de la discusión}

El tratamiento conjunto de la información ha generado un total de 445 referencias codificadas (tabla

3). Este sistema de categorías ha sido creado contemplando unas categorías de análisis establecidas a priori contemplando la posibilidad de que fueran modificables, como indica Rodríguez, Gil, García y Etxebarría (1995). En el caso de la categoría "competencias" se tuvo en cuenta el estudio previo (Eslava-Suanes, González-López y León-Huertas, en prensa). Así como en la categoría "funciones", donde se atendió al catálogo de funciones y competencias del educador o educadora social (ASEDES, 2007). Con respecto al resto de categorías, se realizó un análisis inductivo, siendo las categorías emergentes y construidas a partir del mismo análisis en función de los objetivos que se pretendía conseguir (Echevarría, 2005).

La mayoría de las categorías se encuentran codificadas en la categoría de "dificultades profesionales" (30\%), destacado en estudios precedentes y motivado por la falta de definición de la profesión (Romans, Petrus y Trilla, 2000). Dentro de esta hay que destacar la necesidad de definir y delimitar las funciones y competencias profesionales (6\%). 


\begin{tabular}{|c|c|c|c|c|c|c|c|c|}
\hline Metacategoría & $\begin{array}{l}f \\
S\end{array}$ & $\begin{array}{l}f \\
C\end{array}$ & $\begin{array}{l}f \\
V\end{array}$ & TOTAL & $\%$ & Categoría & $f$ & $\%$ \\
\hline Ser educador social & 7 & 31 & 16 & 54 & 12 & Ser educador social & 54 & 12 \\
\hline \multirow{7}{*}{ Funciones } & \multirow{7}{*}{24} & \multirow{7}{*}{9} & \multirow{7}{*}{42} & \multirow{7}{*}{75} & \multirow{7}{*}{17} & Generación de redes sociales & 9 & 2 \\
\hline & & & & & & Mediación social, cultural y educativa & 35 & 8 \\
\hline & & & & & & $\begin{array}{l}\text { Diseño, implementación y evaluación de } \\
\text { programas y proyectos socioeducativos }\end{array}$ & 14 & 3 \\
\hline & & & & & & Funciones de otros profesionales & 7 & 2 \\
\hline & & & & & & Gestión de instituciones socioeducativas & 2 & 0 \\
\hline & & & & & & Creación de recursos socioeducativos & 6 & 1 \\
\hline & & & & & & $\begin{array}{l}\text { Evaluación de contextos sociales y } \\
\text { educativos }\end{array}$ & 2 & 0 \\
\hline \multirow{4}{*}{ Competencias } & \multirow{4}{*}{13} & \multirow{4}{*}{2} & \multirow{4}{*}{29} & \multirow{4}{*}{44} & \multirow{4}{*}{10} & Competencias crítico-reflexivas & 8 & 2 \\
\hline & & & & & & Competencias sociales & 21 & 4 \\
\hline & & & & & & Competencias funcionales & 12 & 3 \\
\hline & & & & & & Identidad profesional & 3 & 1 \\
\hline $\begin{array}{l}\text { Áreas de acción } \\
\text { socioeducativa }\end{array}$ & 11 & 31 & 28 & 70 & 16 & Áreas de acción socioeducativa & 70 & 16 \\
\hline \multirow{22}{*}{$\begin{array}{l}\text { Dificultades } \\
\text { profesionales }\end{array}$} & \multirow{22}{*}{46} & \multirow{22}{*}{24} & \multirow{22}{*}{65} & \multirow{22}{*}{135} & \multirow{22}{*}{30} & Limitación de funciones y competencias & 28 & 6 \\
\hline & & & & & & Educadores sociales no competentes & 5 & 1 \\
\hline & & & & & & Prestigio o reconocimiento social & 13 & 3 \\
\hline & & & & & & Desconexión teórico-práctica & 6 & 1 \\
\hline & & & & & & Trabajo en equipo & 13 & 3 \\
\hline & & & & & & La institución & 1 & 0 \\
\hline & & & & & & $\begin{array}{l}\text { Carencia de recursos o dificultades para } \\
\text { su acceso }\end{array}$ & 8 & 2 \\
\hline & & & & & & Cuidado profesional-burnout & 3 & 1 \\
\hline & & & & & & Precariedad laboral & 7 & 2 \\
\hline & & & & & & Implicación familiar & 5 & 1 \\
\hline & & & & & & Política & 8 & 2 \\
\hline & & & & & & Regulación & 7 & 2 \\
\hline & & & & & & Toma de decisiones & 4 & 1 \\
\hline & & & & & & Trabajo individual versus colectivo & 2 & 0 \\
\hline & & & & & & Diversidad de ámbitos & 3 & 1 \\
\hline & & & & & & Carencia de profesionales & 2 & 0 \\
\hline & & & & & & Jornada laboral & 7 & 2 \\
\hline & & & & & & Diferencias entre comunidades autónomas & 2 & 0 \\
\hline & & & & & & Carecen de inspector, supervisor & 2 & 0 \\
\hline & & & & & & Burocracia & 1 & 0 \\
\hline & & & & & & Intromisión de profesionales & 7 & 2 \\
\hline & & & & & & $\begin{array}{l}\text { Acceso a puestos de responsabilidad } \\
\text { (techo de cristal) }\end{array}$ & 1 & 0 \\
\hline Suficiente formación & 5 & 8 & 3 & 16 & 4 & Suficiente formación & 16 & 4 \\
\hline $\begin{array}{l}\text { Carencias forma- } \\
\text { tivas }\end{array}$ & 8 & 9 & 11 & 28 & 6 & Carencias formativas & 28 & 6 \\
\hline Oferta formativa & 11 & 3 & 9 & 23 & 5 & Oferta formativa & 23 & 5 \\
\hline Total & 125 & 117 & 203 & 445 & 100 & Total & 445 & 100 \\
\hline
\end{tabular}


La segunda categoría que adquiere mayor importancia es "funciones profesionales" (17\%), destacando la función de mediación social, cultural y educativa (8\%).

Si nos remitimos a las competencias que el educador o educadora social debe poseer para desempeñar sus funciones (10\%), tenemos que centrar la atención concretamente en las competencias sociales (4\%). Sin embargo, las categorías menos representadas se corresponden con la percepción que tienen con respecto a su formación (4\%), las carencias formativas percibidas (6\%) y la valoración de la oferta formativa actual (5\%).

A continuación, se analizan las categorias y sucategorias buscando diferencias en las aportaciones emitidas.

\section{a) Categoría 1: Ser educador o educadora social}

Ser educador o educadora social es acompañar a las personas en los procesos vitales desde una perspectiva social y educativa, como refleja la figura 1.

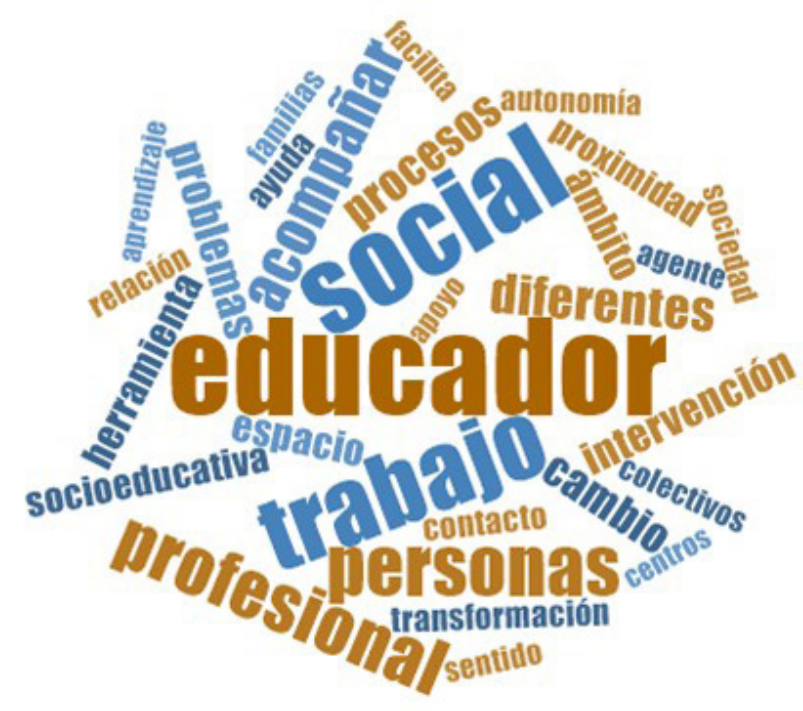

Figura 1. Marca de nube "Ser educador o educadora social"

Sin embargo, en ese acompañar se desprenden otras funciones y connotaciones intrínsecas de la persona que se encuentran implícitas en la misma y que nos describe cómo se percibe el o la profesional de la educación social. En el discurso analizado se puede extraer que este profesional se percibe como un agente social y de cambio comprometido con la sociedad para la que trabaja transformándola desde la conciencia social, siendo un soporte personal y haciendo que la persona se sienta apoyada; siendo capaz de gestionar las herramientas disponibles; de poner en relación a las personas o colectivos con los que trabajan con los recursos y servicios; trabajando desde la próximidad a las personas y el contacto directo y contribuyendo desde un enfoque educativo hacia la autonomía de las personas. 
La figura 2 refleja la aproximación a esta definición desde los diferentes grupos participantes.

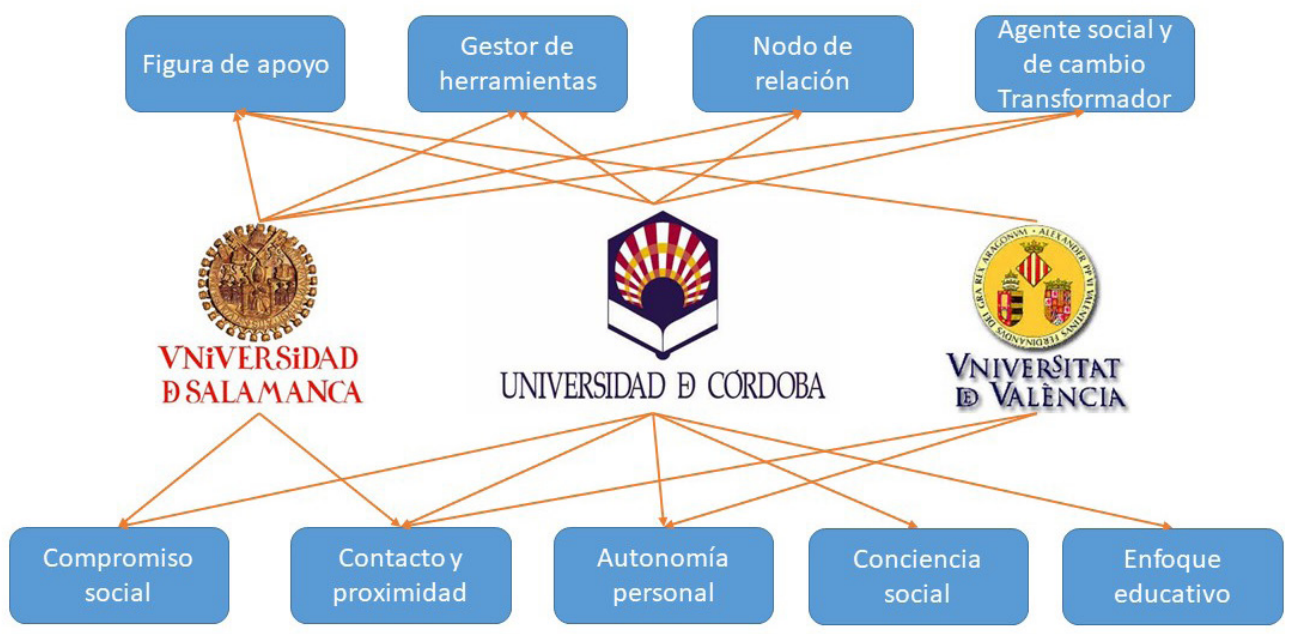

Figura 2. Ser educador o educadora social

\section{b) Categoría 2: Funciones profesionales}

El educador o educadora social se define, en parte, atendiendo a las funciones que realiza, pero cuando esas funciones se materializan en la práctica, se concretan en otras mucho más específicas como (figura 3): la generación de redes sociales; la mediación social, cultural y educativa; el diseño, implementación y evaluación de programas y proyectos socioeducativos; la gestión de instituciones socioeducativas; la creación de recursos socioeducativos y la evaluación de contextos sociales y educativos. Así mismo, se dan situaciones donde estos profesionales se sienten en la necesidad o en la obligación de desempeñar funciones de otros profesionales.

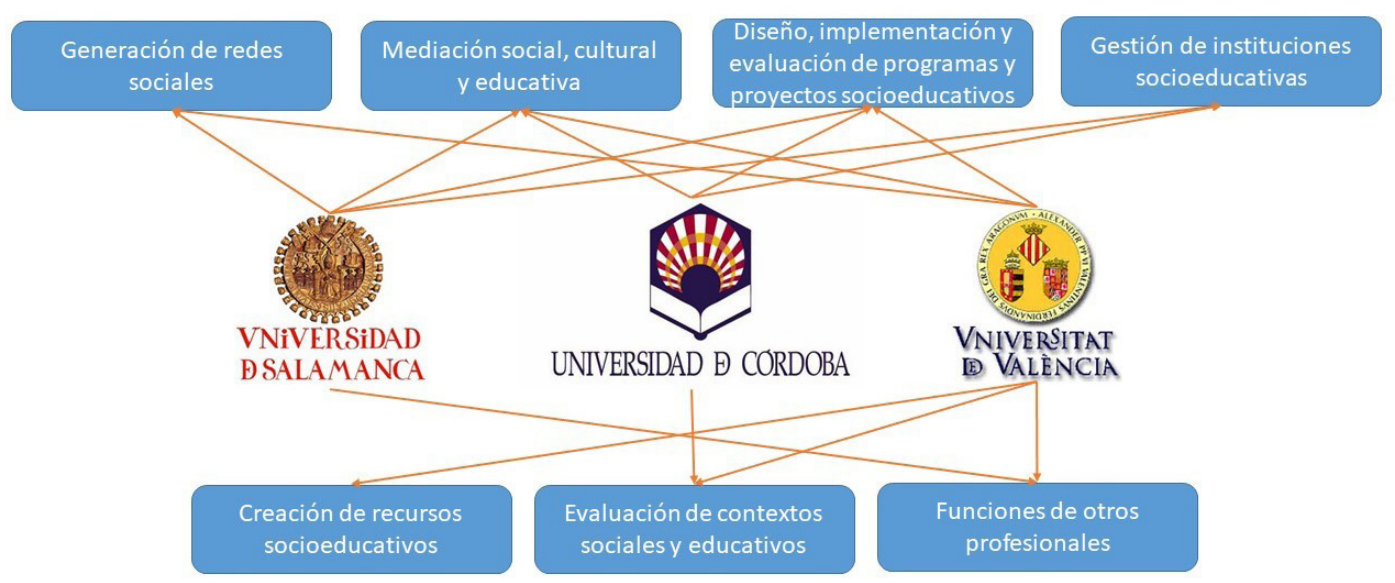

Figura 3. Funciones del educador o educadora social 
c) Categoría 3: Competencias más importantes para el ejercicio de la profesión

Para desempeñar las diferentes funciones, el educador o educadora social precisa armarse de una serie de conocimientos, procedimientos y actitudes que les capaciten para la práctica educativa. Hablamos de las competencias profesionalizadoras agrupadas en cuatro dimensiones competenciales: las competencias crítico-reflexivas, las competencias sociales, las competencias definitorias de la identidad profesional y las competencias funcionales desglosadas en las siguientes: generación de redes sociales; diseño, implementación y evaluación de planes, programas y proyectos; gestión de instituciones socioeducativas; mediación, social, cultural y educativa; y evaluación de contextos sociales y educativos.

Los tres grupos coinciden en señalar las competencias sociales como las más relevantes para el desempeño profesional (Figura 4). Se entiende que la competencia social, junto a la competencia crítico-reflexiva y aquellas definitorias de la identidad profesional van a condicionar las diferentes competencias funcionales.

La segunda competencia que ha tenido más presencia es la relacionada con el desarrollo de habilidades crítico-reflexivas, en la medida en que el desarrollo del pensamiento crítico pueda condicionar la toma de decisiones y la realización de la evaluación inicial diagnóstica.

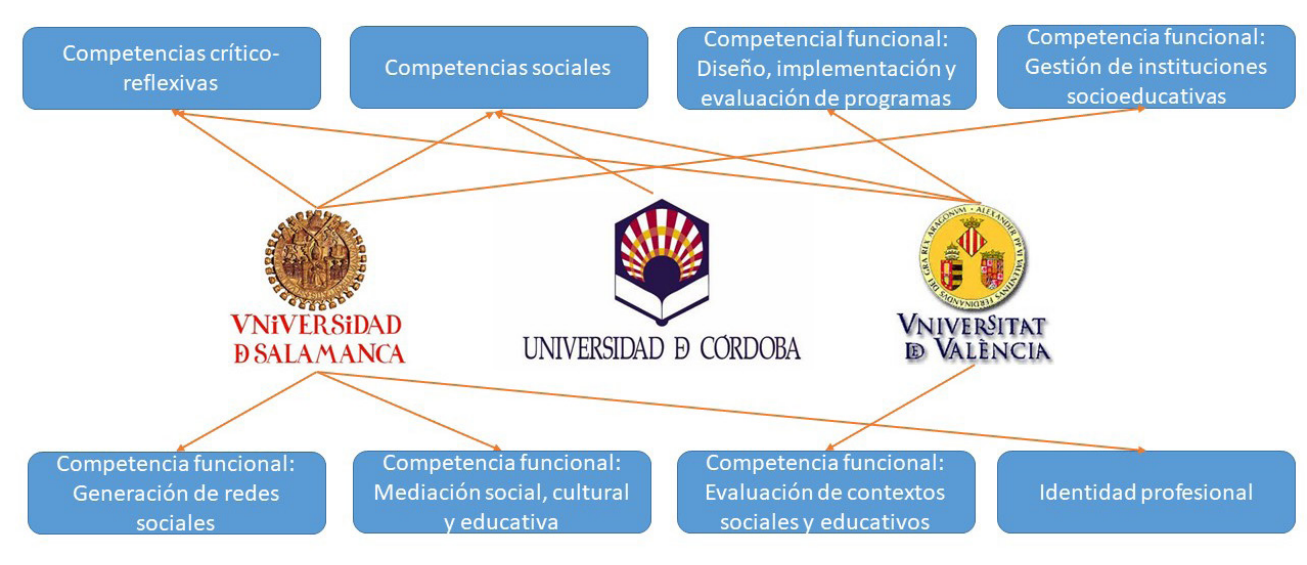

Figura 4. Competencias más importantes para el ejercicio de la profesión

d) Categoría 4: Colectivos, ámbitos y áreas prioritarias de la labor profesional

La figura 5 representa el posicionamiento de los educadores y educadoras sociales con respecto a los colectivos con los que trabajan, definiéndose cinco grupos atendiendo al criterio edad como elemento excluyente: infancia, adolescencia, juventud, adultos y mayores.

El posicionamiento de los diferentes grupos de discusión índica que la acción socioeducativa tiene lugar a lo largo de todo el ciclo evolutivo de las personas, siendo prioritarios adolescencia, seguido de infancia, juventud y adultos. 


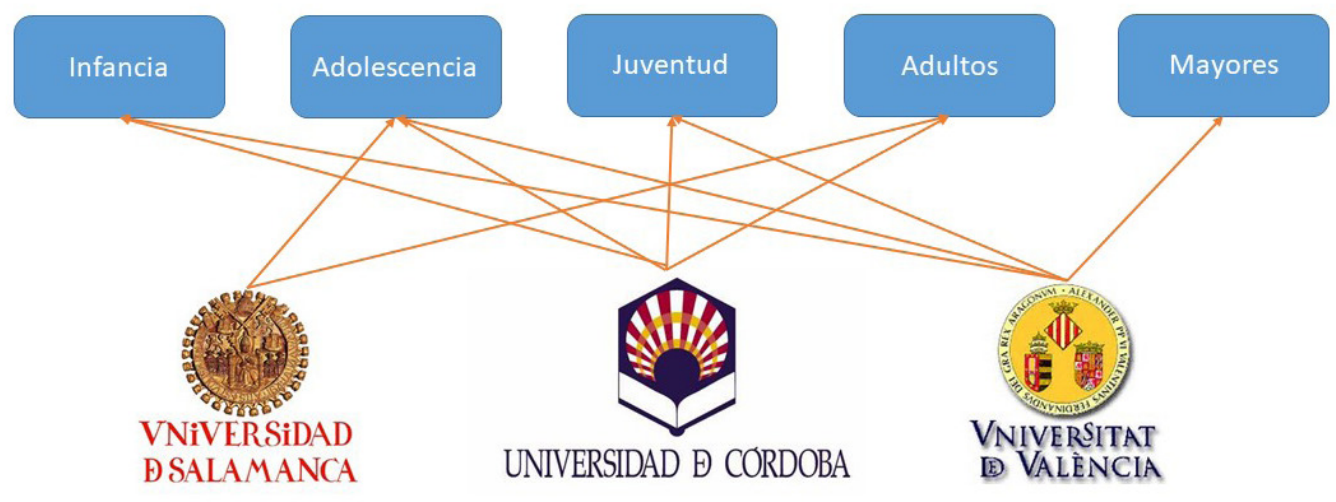

Figura 5. Colectivos a los que va dirigida la acción socioeducativa

Con respecto a los ámbitos desde los cuales se enfoca la acción socioeducativa son seis los identificados en el discurso (Figura 6): educativo, social, laboral, comunitario, judicial y sanitario. Son destacados por los tres grupos el social y el comunitario.

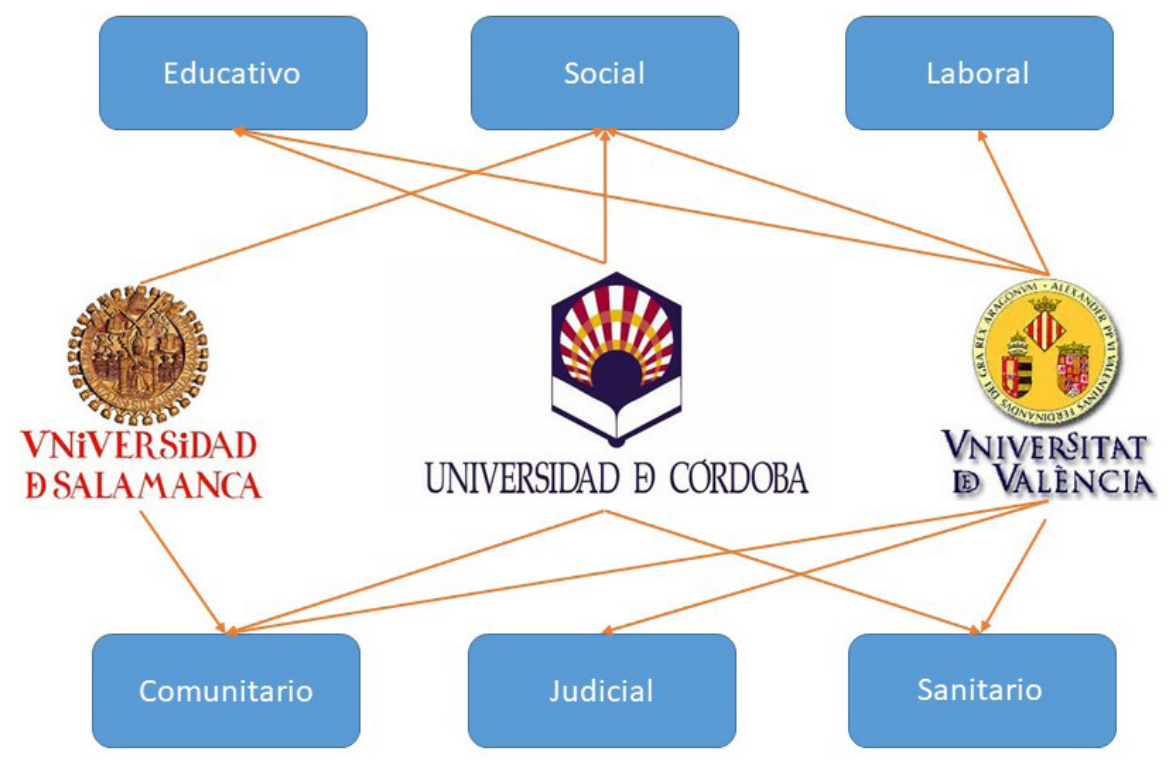

Figura 6. Ámbitos de acción socioeducativa

Finalmente, con respecto a las áreas de actuación, 12 han sido las identificadas como prioritarias: prevención de la dependencia; diversidad funcional y salud mental; medio ambiente; aprendizaje a lo largo de la vida; migraciones, derechos humanos, solidaridad y cooperación internacional; tiempo libre, animación y gestión cultural; familia; igualdad de género y prevención de la violencia; instituciones penitenciarias; desarrollo comunitario y participación ciudadana; y mediación y educación para la convivencia. 
La figura 7 indica que la mayoría de las áreas han sido contempladas como prioritarias por todos los educadores y educadoras sociales. No obstante, el área considerada prioritaria únicamente por el grupo de discusión llevado a cabo en Córdoba ha sido "Medio ambiente".

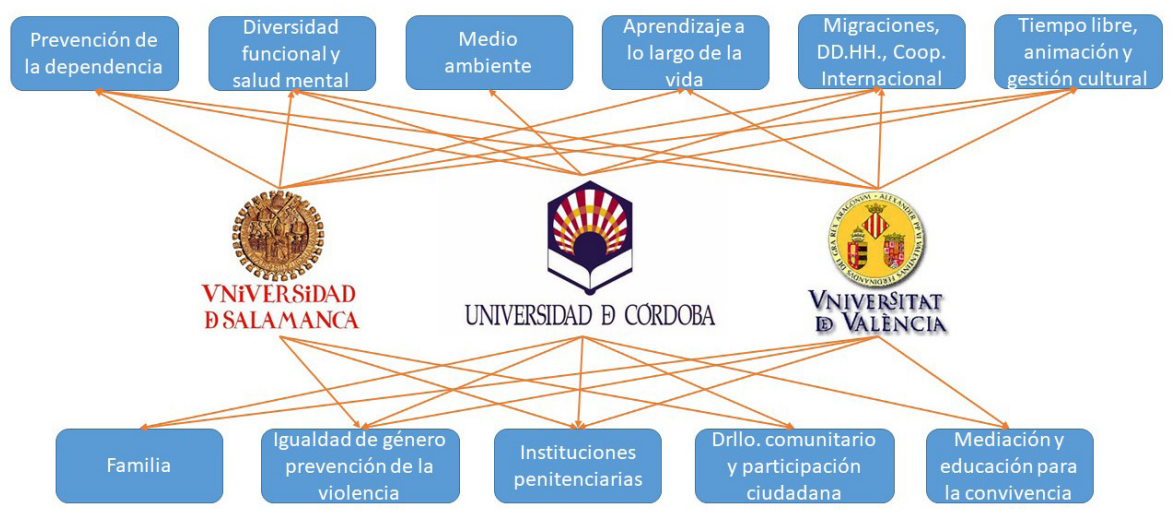

Figura 7. Áreas de acción socioeducativa

e) Categoría 5: Dificultades halladas en el desempeño profesional

La figura 8 da cuenta de aquellas dificultades más significativas manifestadas en su desempeño profesional, siendo las coincidentes en los tres grupos las siguientes:

- La precariedad laboral con respecto a la incertidumbre y falta de garantía de las condiciones del trabajo y el recibimiento de un salario inferior al de su categoría laboral.

- La carencia de recursos o las dificultades para acceder a ellos, tanto monetarios como de infraestructuras.

- Limitación de funciones y competencias, en lo referido al desconocimiento social y de los propios empleadores de las funciones y competencias de este colectivo.

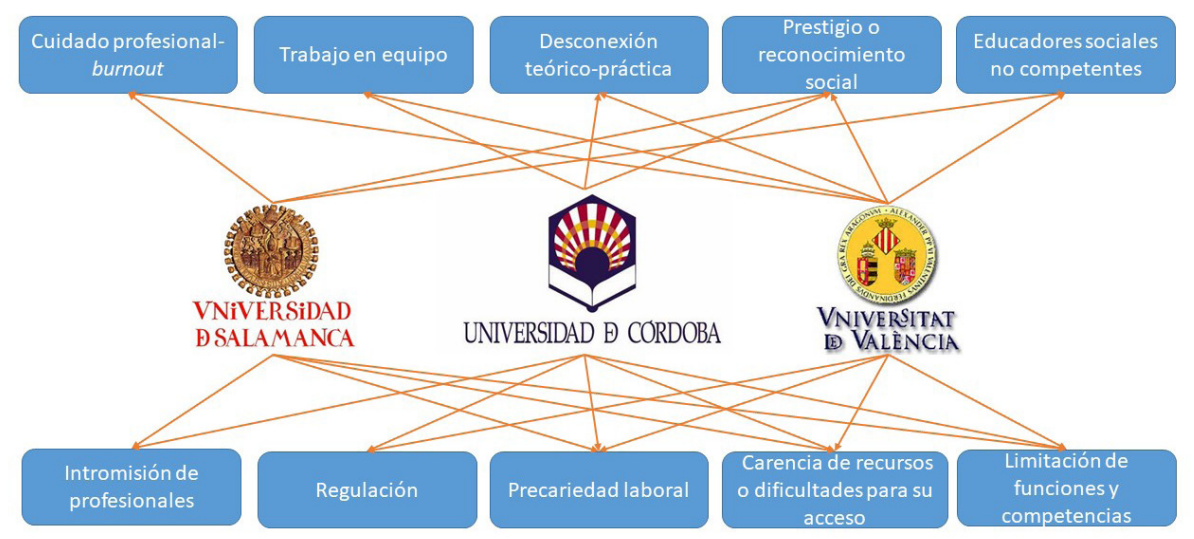

Figura 8. Consenso sobre las ditıcultades halladas en el ejercicio de la educación social 
f) Categoría 6: Capacitación para el ejercicio profesional

Los educadores y educadoras sociales consideran que una vez que concluyen la formación inicial no se encuentran capacitados para desempeñar la profesión. En su discurso se localizan tres postulados: la formación universitaria es insuficiente al ser demasiado generalista; ninguna formación universitaria capacita plenamente para el desempeño profesional; y que nunca se van a considerar lo suficientemente formados, ya que al ser una profesión cambiante, las necesidades de los sujetos y colectivos de la acción socioeducativa van a ser previos, generándose la necesidad formativa.

La figura 9 refleja estos posicionamientos, apreciándose consenso en considerar que sus carencias formativas se deben a que la formación universitaria es insuficiente.

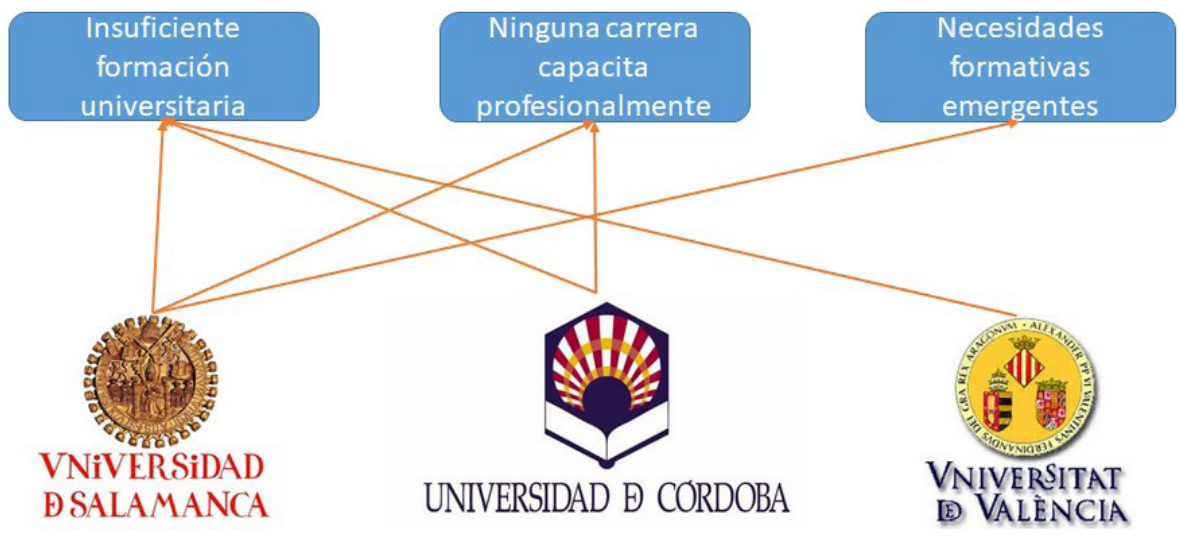

Figura 9. Posicionamiento frente a la capacitación para el ejercicio profesional

\section{g) Categoría 7: Principales carencias formativas}

Con respecto a las carencias formativas (Figura 10), ocho han sido las debilidades encontradas:

- Conocimiento y desarrollo personal, en lo referido al control emocional y a la gestión de las emociones tanto en uno mismo como en los demás.

- Falta de referentes teóricos, destacado principalmente por los educadores y educadoras sociales que han accedido a la educación social a través de la habilitación para su ejercicio.

- Acercamiento a los colegios profesionales de referencia: qué son, para qué sirven, qué me pueden ofrecer, etc.

- Innovación en el desarrollo de planes, programas y proyectos, como herramienta principal desde la que se planifica la acción socioeducativa.

- Legislación en las diferentes áreas de actuación.

- Inserción laboral, en lo referido al desconocimiento de los diferentes recursos e instituciones que existen y el acceso a los mismos. 
- Técnicas e instrumentos de recogida de información tanto para garantizar el diagnóstico como para el seguimiento de una acción.

- Formación para la acción en diferentes áreas específicas como: familia, mediación y educación para la convivencia, diversidad funcional y salud mental, migraciones, derechos humanos, solidaridad y cooperación internacional.

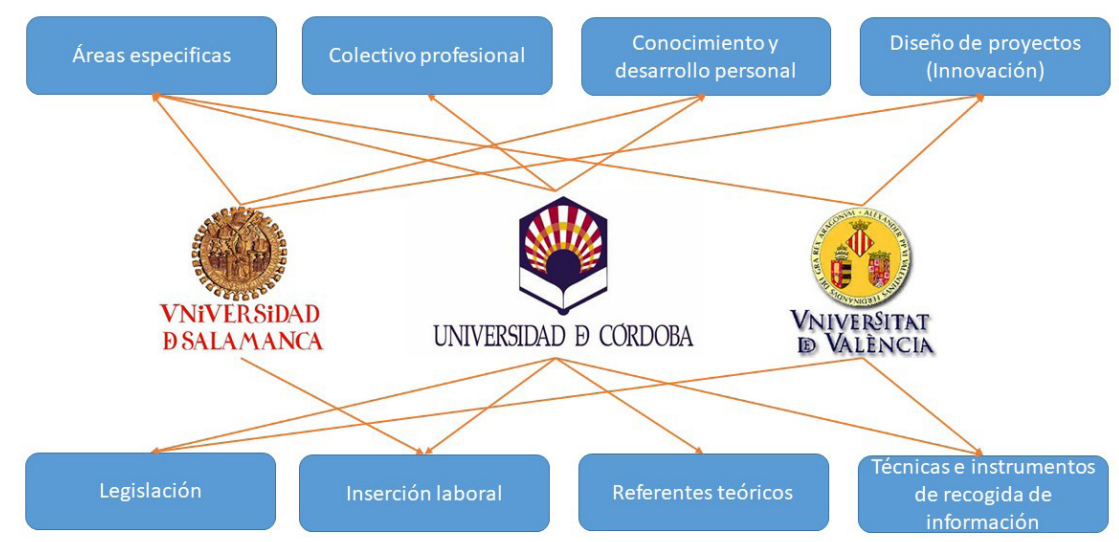

Figura 10. Carencias formativas

\section{h) Categoría 8: Oferta formativa}

Los educadores y educadoras sociales resuelven que la oferta formativa existente no garantiza la formación continua, ya que no responde a sus necesidades, sino que se rige por una tendencia o moda, garantizando su visibilidad social; la mayoría de los cursos y actividades ofertadas no están reconocidas por los colegios profesionales; no son de fácil acceso, en la medida en que precisan de un gran desembolso económico; no son lo suficientemente específicos o especializados; y no son profesionalizadoras, ya que la mayoría son impartidas por profesionales que no conocen la práctica socioeducativa, no facilitando la conexión teórico-práctica (Figura 11).

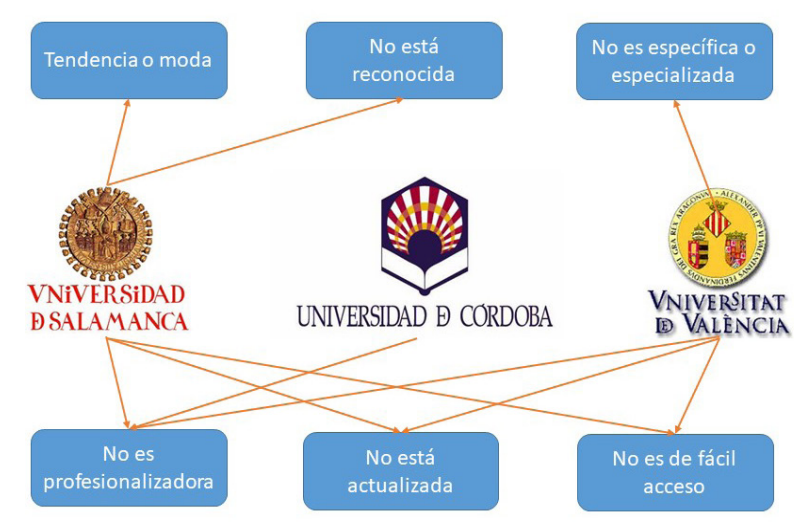

Figura 11. Percepción sobre la oferta formativa actual 


\subsection{Resultados de las matrices CAME}

El análisis de la situación de la profesión presentado en la tabla 4 recoge las propuestas de mejora de manera conjunta estimadas por el grupo de 23 profesionales, así como la postura diferencial de cada grupo consultado.

\begin{tabular}{|c|c|c|c|c|c|c|c|c|c|c|c|}
\hline \multicolumn{6}{|c|}{ Corregir } & \multicolumn{6}{|c|}{ Afrontar } \\
\hline Categorías & $f$ & $\%$ & S & C & V & Categorías & $f$ & $\%$ & S & C & V \\
\hline Relaciones sociales & 1 & 2 & 1 & - & - & Definición de contextos & 1 & 2 & 1 & - & - \\
\hline Optimización de recursos & 2 & 5 & 2 & - & - & Mediación & 1 & 2 & 1 & - & - \\
\hline $\begin{array}{l}\text { Adaptación de la } \\
\text { intervención al contexto }\end{array}$ & 2 & 5 & 2 & - & - & $\begin{array}{l}\text { Relación profesionales- } \\
\text { universidad }\end{array}$ & 1 & 2 & - & 1 & - \\
\hline Investigación & 2 & 5 & - & 2 & - & Planificación & 2 & 5 & - & 2 & - \\
\hline $\begin{array}{l}\text { Relación profesional- } \\
\text { universidad }\end{array}$ & 1 & 2 & - & 1 & - & $\begin{array}{l}\text { Delimitación de funciones y } \\
\text { competencias }\end{array}$ & 3 & 7 & 1 & 2 & - \\
\hline $\begin{array}{l}\text { Delimitación de ámbitos } \\
\text { profesionales }\end{array}$ & 3 & 7 & - & 3 & - & Generación de recursos & 4 & 9 & 2 & 2 & - \\
\hline Innovación & 4 & 9 & 1 & - & 3 & Relaciones sociales & 2 & 5 & - & 1 & 1 \\
\hline Salud y cuidado profesional & 3 & 7 & - & 1 & 2 & Investigación & 4 & 9 & - & 3 & 1 \\
\hline Formación & 16 & 36 & 3 & 9 & 4 & Resignación & 3 & 7 & - & 2 & 1 \\
\hline $\begin{array}{l}\text { Generación de redes } \\
\text { sociales }\end{array}$ & 5 & 11 & 1 & 2 & 2 & Formación & 2 & 5 & - & 1 & 1 \\
\hline \multirow[t]{2}{*}{$\begin{array}{l}\text { Delimitación de funciones y } \\
\text { competencias }\end{array}$} & 5 & 11 & 2 & 2 & 1 & $\begin{array}{l}\text { Generación de redes } \\
\text { sociales }\end{array}$ & 10 & 23 & 3 & 4 & 3 \\
\hline & & & & & & Empoderamiento & 10 & 23 & 3 & 3 & 4 \\
\hline Total & 44 & 100 & 12 & 20 & 12 & Total & 43 & 100 & 11 & 21 & 11 \\
\hline \multicolumn{6}{|c|}{ Mantener } & \multicolumn{6}{|c|}{ Explotar } \\
\hline Categorías & $f$ & $\%$ & S & C & V & Categorías & $f$ & $\%$ & $S$ & C & V \\
\hline Diversidad de contextos & 1 & 2 & 1 & - & - & Coyuntura política & 1 & 2 & - & - & 1 \\
\hline $\begin{array}{l}\text { Adaptación de la } \\
\text { intervención al contexto }\end{array}$ & 2 & 5 & 2 & - & - & Identidad profesional & 5 & 12 & 2 & 3 & - \\
\hline Relaciones sociales & 2 & 5 & 1 & 1 & - & Diversidad de contextos & 6 & 14 & 2 & 4 & - \\
\hline Pensamiento crítico & 3 & 7 & 1 & - & 2 & Adecuación a la realidad & 3 & 7 & 2 & - & 1 \\
\hline Optimizar recursos & 3 & 7 & 2 & - & 1 & Innovación & 5 & 12 & - & 3 & 2 \\
\hline Desconexión laboral & 2 & 5 & 1 & - & 1 & Investigación & 3 & 7 & 1 & 2 & - \\
\hline Innovación & 4 & 10 & - & 2 & 2 & Formación & 6 & 14 & 3 & 2 & 1 \\
\hline Actitud & 6 & 14 & - & 4 & 2 & Optimización de recursos & 4 & 10 & 1 & 2 & 1 \\
\hline Formación & 6 & 14 & - & 4 & 2 & Trabajo en red & 9 & 21 & 2 & 4 & 3 \\
\hline Identidad profesional & 6 & 14 & 2 & 3 & 1 & & & & & & \\
\hline Generación de redes & 7 & 17 & 1 & 5 & 1 & & & & & & \\
\hline Total & 42 & 100 & 11 & 19 & 12 & Total & 42 & 100 & 13 & 20 & 9 \\
\hline
\end{tabular}


Para corregir sus debilidades a la hora de enfrentarse a la profesión, coinciden en tres aspectos fundamentales:

- Formación: precisan una formación más práctica y especializada que les capacite para la acción socioeducativa, la toma de decisiones y la investigación en aquellas áreas donde la formación inicial es limitada y generalista.

- Generación de redes sociales: destacan la necesidad de crear equipos de trabajo interdisciplinares y adquirir las habilidades para trabajar en equipo cooperativamente.

- Delimitación de funciones y competencias: precisan empoderarsey valorar su profesión mostrando cuáles son sus funciones y competencias en la práctica, es decir, todas aquellas capacidades que les posibiliten la promoción de la cultura; la generación de redes sociales; la creación de recursos socioeducativos; la mediación social, cultural y educativa; la evaluación de contextos sociales y educativos; el diseño, implementación y evaluación de programas y proyectos socioeducativos; y la gestión de instituciones socioeducativas.

Los educadores y educadoras sociales de Valencia y Salamanca que participaron en el estudio destacan la innovación desde tres puntos de vista: como estrategia para seguir motivados, con la finalidad de mejorar la acción socioeducativa y con el objetivo de contribuir al reconocimiento de la profesión.

Para afrontar las amenazas profesionales todos los grupos informantes destacan la necesidad de empoderar la profesión, reivindicando su definición y reconocimiento a través de los colegios profesionales, así como a través de la calidad del trabajo de los propios profesionales. Así mismo, subrayan la necesidad de trabajar en equipo y de construir redes de trabajo.

Losy las profesionales de Salamanca y Córdoba señalan la necesidad de definiry delimitar susfunciones y competencias para afrontar amenazas como la intromisión profesional y ser emprendedores en la generación de recursos o haciendo un uso efectivo de los existentes. Las educadoras y los educadores sociales de Córdoba y Valencia consideran necesario aprovechar sus competencias sociales y el trabajo con las personas para adecuar la acción socioeducativa, paliar sus carencias formativas a través de la formación continua, hacer investigación y darla a conocer.

Como aspectos a mantener, se resalta la identidad profesional, es decir, la reivindicación que actualmente se está llevando por el reconocimiento de la profesión; así como la generación de redes, en lo que respecta a cómo el trabajo desde lo colectivo puede contribuir a la cohesión social, hacer fuerza en el reconocimiento de la profesión y servir de recurso para la propia acción socioeducativa.

Con respecto al resto de categorías, Salamanca y Córdoba señalan la necesidad de mantener y 
desarrollar sus competencias sociales para mejorar las relaciones sociales. Los profesionales de Salamanca y Valencia insisten en mantener el pensamiento crítico para construir profesión, continuar optimizando los recursos disponibles, y con respecto al cuidado profesional, advierten de la necesidad de separar el terreno laboral de lo personal. Por otro lado, los profesionales de Córdoba y Valencia destacan seguir manteniendo el compromiso y el interés por la formación continua y la innovación socioeducativa.

Como aspectos a explotar, vuelven a aparecer elementos como el trabajo en red, la optimización de los recursos existentes y las oportunidades de formación continua. Los educadores y educadoras sociales de Salamanca y Córdoba insisten en explotar el movimiento actual por la construcción de la identidad profesional, aprovechar la diversidad de contextos socioeducativos donde desempeñarse profesionalmente para incorporarse al mercado laboral o para elegir el colectivo con el que se quiere trabajar, y hacer investigación dándola a conocer para dejar constancia del trabajo que se realiza y crear antecedentes, por ejemplo de las innovaciones en la acción socioeducativa, aspecto en el que inciden los grupos de Córdoba y Valencia. Finalmente, los educadores y educadoras sociales de Salamanca y Valencia destacan la oportunidad que les brinda la profesión de estar constantemente en contacto con las personas para adecuar la acción socioeducativa a la realidad.

\section{Conclusiones}

La necesidad de revisión de los perfiles competenciales recogidos en los diferentes planes de estudio manifestada es entendida como medio para asegurar, en el desempeño profesional, la mejora de la respuesta socioeducativa, mitigar las dificultades profesionales y remitir las carencias formativas manifestadas en los resultados expuestos. Si bien, desde el ámbito académico, el alumnado se muestra satisfecho con la formación recibida (Losada-Puente, Muñoz-Cantero y Espiñeira-Bellón, 2015). Desde el ámbito profesional, dicha revisión viene siendo una demanda, no mostrándose de acuerdo con el modo de proceder en la instauración del título de Graduado o Graduada en Educación Social (Sánchez-Valverde, 2011).

Teniendo en cuenta que la finalidad es conocer la percepción de los educadores y educadoras en ejercicio de su profesión, los resultados extraídos contribuyen a redefinir el perfil competencial, ya que se acomodan para aportar una panorámica de la situación profesional del educador o educadora social.

El modelo previo, definido a través de dos metacategorías de análisis, las competencias básicas y las competencias profesionales, pasa a entenderse de manera global e integral, como un modelo competencial llamado a enriquecer al alumnado en todos los ámbitos de su desarrollo desde cuatro 
ámbitos: el personal, el social, el intelectual y el práctico, promoviendo una formación polivalente e integral (Zabalza, 2008).

Se entiende, por tanto, que en el modelo competencial diseñado todas las competencias son profesionales, ya que incluyen al conjunto de capacidades que posee un individuo para desempeñarse profesionalmente (Guzmán, 2012). Ser educador o educadora social, tal y como se define el propio profesional, tiene lugar a través de la conjugación de los diferentes componentes que constituyen una competencia, como el compromiso social, el apoyo o acompañamiento personal en contacto directo, la capacidad para gestionar herramientas disponibles, de poner en relación a las personas o colectivos con los que trabajan con los recursos y servicios, trabajando hacia el logro de la autonomía de las personas.

No obstante, el modelo competencial propuesto mantiene las 6 dimensiones competenciales: comunicativas, crítico-reflexivas, sociales, disciplinares, funcionales y definitorias de la identidad profesional. Entendiendo estas dimensiones en términos de componentes cuya conjunción permite dar una respuesta eficaz a una tarea, concretándose en la competencia. La aplicación en contextos específicos de la competencia adquirida supone de la demostración de la misma (Fullana, 2009).

De las seis dimensiones expuestas, los educadores y educadoras sociales han destacado como prioritarias cuatro: las competencias crítico-reflexivas, las competencias sociales, las competencias definitorias de la identidad profesional y las competencias funcionales desglosadas en las siguientes: generación de redes sociales; diseño, implementación y evaluación de planes, programas y proyectos; gestión de instituciones socioeducativas; mediación, social, cultural y educativa; y evaluación de contextos sociales y educativos. Coincidiendo con investigaciones previas donde los educadores y educadoras sociales valoraban las competencias interpersonales, instrumentales y sistémicas, por encima de los conocimientos disciplinarios e incluso por encima de algunas competencias funcionales como es el caso de las competencias sociales (Fullana, Pallisera y Planas, 2011).

El perfil competencial con el que el profesional de la educación social implicado en este estudio se siente identificado está compuesto por 23 competencias agrupadas en seis dimensiones recogidas en la tabla 5: competencias comunicativas, competencias crítico-reflexivas, competencias sociales, conocimientos disciplinares, competencias funcionales y competencias definitorias de la identidad profesional. 


\begin{tabular}{|c|c|c|}
\hline \multicolumn{3}{|r|}{ FASE 3} \\
\hline Dimensión & Elementos competenciales & Competencia \\
\hline \multirow{2}{*}{$\begin{array}{l}\text { Competencias } \\
\text { comunicativas }\end{array}$} & Comunicación mediática & $\begin{array}{c}\text { Hacer un uso efectivo de las tecnologías de la información y la comunicación } \\
\text { aplicadas a la formación y a la comunicación en los procesos de gestión, } \\
\text { organización y acción socioeducativa. }\end{array}$ \\
\hline & $\begin{array}{l}\text { Uso y dominio de una lengua } \\
\text { extranjera }\end{array}$ & $\begin{array}{l}\text { Dominar una segunda lengua de forma oral y escrita con el fin de favorecer la } \\
\text { comunicación y las relaciones al trabajar en entornos multiculturales. }\end{array}$ \\
\hline \multirow{4}{*}{$\begin{array}{l}\text { Competencias } \\
\text { crítico-reflexivas }\end{array}$} & $\begin{array}{l}\text { Comprensión de los referentes } \\
\text { teóricos y contextuales de la } \\
\text { educación social }\end{array}$ & $\begin{array}{l}\text { Comprender los referentes teóricos y contextuales que configuran al ser } \\
\text { humano como protagonista de la educación y su aplicación a los distintos } \\
\text { ámbitos y grupos de acción. }\end{array}$ \\
\hline & \multirow{2}{*}{ Pensamiento crítico } & $\begin{array}{l}\text { Identificar y emitir juicios razonados sobre problemas socioeducativos } \\
\text { relacionados con la práctica profesional. }\end{array}$ \\
\hline & & $\begin{array}{l}\text { Tomar decisiones respecto a la práctica socioeducativa teniendo en cuenta las } \\
\text { consecuencias para todas las partes implicadas. }\end{array}$ \\
\hline & $\begin{array}{l}\text { Selección y gestión de la } \\
\text { información }\end{array}$ & $\begin{array}{c}\text { Analizar, sintetizare interpretarla información que proporciona el trabajo } \\
\text { cotidiano y los medios de información y comunicación con la finalidad de } \\
\text { mejorar las estrategias profesionales de acción. }\end{array}$ \\
\hline \multirow{2}{*}{$\begin{array}{l}\text { Competencias } \\
\text { sociales }\end{array}$} & \multirow{2}{*}{ Relaciones sociales } & $\begin{array}{l}\text { Desarrollar una actitud empática, respetuosa, asertiva, solidaria y de confianza } \\
\text { hacia las personas e instituciones sujetos de la acción socioeducativa. }\end{array}$ \\
\hline & & $\begin{array}{c}\text { Propiciar el empoderamiento de la población para que reconozca como } \\
\text { protagonista de su desarrollo personal y comunitario. }\end{array}$ \\
\hline \multirow{6}{*}{$\begin{array}{l}\text { Conocimientos } \\
\text { disciplinares }\end{array}$} & Pedagogía Social & $\begin{array}{l}\text { Conocer e interpretar la deontología, evolución y modelos del ejercicio de la } \\
\text { profesión de la educación social, así como los supuestos pedagógicos para la } \\
\text { adecuación profesional a los diferentes ámbitos de acción socioeducativa. }\end{array}$ \\
\hline & $\begin{array}{c}\text { Fundamentos teóricos y } \\
\text { legislativos de la Educación } \\
\text { Social } \\
\end{array}$ & $\begin{array}{c}\text { Conocer la evolución del conocimiento educativo al amparo de las teorías y } \\
\text { enfoques pedagógicos y bases legislativas que a lo largo del quehacer educativo } \\
\text { se han ido construyendo. }\end{array}$ \\
\hline & Inclusión socioeducativa & $\begin{array}{c}\text { Conocer los principios y fundamentos de acción de la inclusión para la } \\
\text { adecuación de la respuesta socioeducativa. }\end{array}$ \\
\hline & Psicología del desarrollo & $\begin{array}{l}\text { Conocer los estadios evolutivos y el desarrollo madurativo en las diferentes } \\
\text { áreas: motora, cognitiva, comunicativa y socioafectiva, con la finalidad de } \\
\text { adecuar la acción socioeducativa de la población con la que se trabaja. }\end{array}$ \\
\hline & Sociología de la educación & $\begin{array}{l}\text { Conocer y comprender la dinámica de construcción social de la realidad, el } \\
\text { proceso de socialización de las personas. }\end{array}$ \\
\hline & Antropología & $\begin{array}{l}\text { Conocer y aplicar la mirada antropológica en el desarrollo de su profesión a } \\
\text { través del uso crítico del relativismo cultural en normas sociales, políticas, } \\
\text { filosóficas y religiosas. }\end{array}$ \\
\hline \multirow{7}{*}{$\begin{array}{l}\text { Competencias } \\
\text { funcionales }\end{array}$} & Promoción de la cultura & $\begin{array}{c}\text { Dinamizar actividades que fomenten la transformación sociocultural desde el } \\
\text { respeto a los valores culturales de la diversidad. }\end{array}$ \\
\hline & Generación de redes sociales & $\begin{array}{c}\text { Aplicar las distintas estrategias metodológicas y técnicas de acción individual, } \\
\text { grupal y comunitaria para facilitar las interacciones sociales. }\end{array}$ \\
\hline & $\begin{array}{l}\text { Creación de recursos } \\
\text { socioeducativos }\end{array}$ & $\begin{array}{l}\text { Elaborar, utilizar y evaluar recursos educativos e instrumentos de recogida de } \\
\text { información para enriquecer y mejorar los procesos y contextos educativos y } \\
\text { sociales. }\end{array}$ \\
\hline & $\begin{array}{l}\text { Mediación social, cultural y } \\
\text { educativa }\end{array}$ & $\begin{array}{l}\text { Aplicar técnicas de resolución de conflictos para prevenir, mediar e intervenir, } \\
\text { asesorando, acompañando y promocionando a personas y grupos. }\end{array}$ \\
\hline & $\begin{array}{l}\text { Evaluación de contextos } \\
\text { sociales y educativos }\end{array}$ & $\begin{array}{c}\text { Investigar los contextos sociales, culturales y educativos para detectar las } \\
\text { demandas de acción en escenarios socioeducativos. }\end{array}$ \\
\hline & $\begin{array}{l}\text { Diseño, implementación y } \\
\text { evaluación de programas y } \\
\text { proyectos socioeducativos }\end{array}$ & $\begin{array}{l}\text { Elaborar, aplicar y evaluar planes, programas y proyectos de acción } \\
\text { socioeducativa en diversos contextos. }\end{array}$ \\
\hline & $\begin{array}{l}\text { Gestión de instituciones } \\
\text { socioeducativas }\end{array}$ & $\begin{array}{l}\text { Gestionar y coordinar centros, instituciones y asociaciones de acuerdo a los } \\
\text { diferentes contextos y necesidades en los ámbitos de acción socioeducativa. }\end{array}$ \\
\hline \multirow[b]{2}{*}{$\begin{array}{l}\text { Identidad } \\
\text { profesional }\end{array}$} & \multirow[b]{2}{*}{ Identidad profesional } & Mantener el compromiso ético en la acción e investigación socioeducativa. \\
\hline & & $\begin{array}{l}\text { Desarrollar y fortalecer el conocimiento de sí mismo (autocuidado, autocontrol, } \\
\text { equilibrio emocional, manejo del estrés y control de la incertidumbre durante la } \\
\text { acción socioeducativa) como base del crecimiento, integración y actualización } \\
\text { de las potencialidades profesionales. }\end{array}$ \\
\hline
\end{tabular}




\section{Referencias}

Álvarez Rojo, V. (1990). Los grupos de discusión. Cuestiones Pedagógicas: Revista de ciencias de la educación, 6-7, 201-208.

ASEDES. (2007). Documentos profesionalizadores. Recuperado de: http://www.eduso.net/ archivo/docdow.php?id=143

Barbour, R. (2013). Los grupos de discusión en investigación cualitativa. Madrid: Ediciones Morata.

Bisquerra, R. (2004). Metodología de la investigación educativa. Madrid: La Muralla.

Callejo, J. (2001). El grupo de discusión: introducción a una práctica de investigación. Barcelona: Ariel.

Canales, M. y Peinado, A. (1995). Grupo de discusión. En J. M. Delgado y J. Gutiérrez (Coords.), Métodos y técnicas cualitativas de investigación en ciencias sociales (pp. 288-316). Madrid: Síntesis.

Creswell, J. W. \& Plano Clark, V. L. (2007). Designing and Conducting Mixed Methods Research. Thousand Oaks: Sage.

Echevarría, G. (2005). Análisis Cualitativo por Categorías. Universidad Academia de Humanismo Cristiano. Escuela de Psicología. Santiago.

Eslava-Suanes, M. D., González-López, I. y León-Huertas, C. (en prensa). Discusión de competencias en el ámbito universitario: revisión del perfil del educador social. Cultura y Educación.

Fábregues, S., Meneses, J., Rodríguez-Gómez, D. y Paré, M. H. (2016). Técnicas de investigación social y educativa. Barcelona: Editorial UOC.

Fullana, J. (2009). Guía para la evaluación de competencias en educación social. Barcelona: Agència per a la Qualitat del Sistema Universitari de Catalunya.

Fullana, J., Pallisera, M. y Planas, A. (2011). Las competencias profesionales de los educadores sociales como punto de partida para el diseño curricular de la formación universitaria. Un estudio mediante el método Delphi. Revista Iberoamericana de Educación, 15(1), 1-13. 
Gil, J. (1992). La metodología de investigación mediante grupos de discusión. Enseñanza \& Teaching: Revista interuniversitaria de didáctica, 10, 199-212.

Guzmán, F. (2012). El concepto de competencias. Revista Iberoamericana de Educación, 4(60), $1-13$.

Hernández, R., Fernández y C. Baptista, P. (2006). Metodología de la investigación. México: McGraw-Hill Interamericana.

Huertas, E. y Vigier, F. J. (2010). El grupo de discusión como técnica de investigación en la formación de traductores: dos casos de su aplicabilidad. Entreculturas, 2, 181-196.

Losada-Puente, L.; Muñoz-Cantero, J. M.; Espiñeira-Bellón, E. M. (2015). Perfil, funciones y competencias del educador social a debate: análisis de la trayectoria de la formación de profesionales de la educación social. Educació Social. Revista d'Intervenció Socioeducativa, 60 , pp. 59-76.

Mena, A. M. y Méndez, J. M. (2009). La técnica de grupo de discusión en la investigación cualitativa. Aportaciones para el análisis de los procesos de interacción. Revista Iberoamericana de Educación, 3(49).

Romans, M., Petrus, A. y Trilla, J. (2000). De profesión: educador(a) social. Barcelona: Paidós.

Sánchez-Valverde, C. (2011). La gestación del título de grado, desde la mirada del colectivo profesional. Revista de Educación Social, 13, 1-12. Recuperado de: http://www.eduso.net/res/ pdf/13/asedes_res_13.pdf

Suárez, M. (2005). El grupo de discusión: una herramienta para la investigación cualitativa. Barcelona: Laertes.

Zabalza, M. A. (2008). El trabajo por competencias en la enseñanza universitaria. En I. Rodríguez Escanciano (Ed.), El nuevo perfil del profesor universitario en el EEES: claves para la renovación metodológica (pp. 79-114). Valladolid: Universidad Europea Miguel de Cervantes. 